\title{
A morphological and molecular description of a new Teleopsis species (Diptera: Diopsidae) from Thailand
}

\author{
MIHÁLY FÖLDVÁRI ${ }^{1}$, ANDREW POMIANKOWSKI ${ }^{2}$, SAMUEL COTTON ${ }^{3} \&$ MARTIN CARR $^{4}$ \\ ${ }^{1}$ Hungarian Natural History Museum, Baross u.13, H-1088 Budapest, Hungary. E-mail: foldvari@nhmus.hu \\ ${ }^{2}$ The Galton Laboratory, Department of Biology, and CoMPLEX, University College, London, 4 Stephenson Way, London, NW1 $2 H E$, \\ UK.E-mail: ucbhpom@ucl.ac.uk \\ ${ }^{3}$ Department of Ecology \& Evolution, University of Lausanne, Le Biophore, Lausanne, CH - 1015, Switzerland. \\ E-mail: samuel.cotton@unil.ch \\ ${ }^{4}$ Department of Biology, University of York, Heslington, York, YO10 5YW, UK. E-mail: mc528@york.ac.uk
}

\begin{abstract}
A new species of Teleopsis (Diptera, Diopsidae) from Chiang Mai, Thailand is described and illustrated. Teleopsis thaii Földvári \& Carr is shown to be a member of a species group, termed the dalmanni species group, along with three previously described species. Presented here are a morphological description of T. thaii and an allometric comparison of the species with other members of the Teleopsis genus. We also present multi-gene phylogenetic analyses to highlight the possible position of $T$. thaii within the dalmanni species group.
\end{abstract}

Key words: Diopsidae, Teleopsis, Thailand, new species, eye span allometry, molecular phylogeny, dalmanni species group

\section{Introduction}

The diopsid stalk-eyed flies are a morphologically distinct family of the Schizophoran diptera, with both males and females of all species possessing laterally extended head morphologies. There are approximately 160 described species within the family, although this figure is increasing (Papp et al. 1997, Feijen 1999, Carr et al. 2006a) and the family is currently undergoing taxonomic revision (Baker et al. 2001, Kotrba \& Balke 2006). Recent molecular studies have shown that the genera Teleopsis and Cyrtodiopsis are in fact paraphyletic with respect to each other, form a monophyletic group and should be considered as a single genus (Baker et al. 2001, Meier \& Baker 2002). Under this revision, species previously named as Cyrtodiopsis are now termed Teleopsis species.

Species from the genus Teleopsis are mainly found in South East Asia (Feijen 1998). Many of the described Teleopsis species show sexual dimorphism within their eyespan, with males showing the greater exaggeration in head morphology, a trait strongly linked to sexual selection. Sexually dimorphic species from Malaysia have been the focus of much of the research in the study of sexual selection within the stalk-eyed flies (David et al. 2000, Hingle et al. 2001, Cotton et al. 2004).

Here we describe a new species of Teleopsis from the Doi Suthep, Chiang Mai, Thailand. A viable laboratory population has been established at University College, London from individuals collected from this region. Using phylogenetic analysis of four partial gene sequences we have placed this species within a newly termed species group along with T. currani (Shillito), T. dalmanni (Wiedemann) and T. whitei (Curran). This new group has been named the dalmanni species group (after the species, T. dalmanni). We have described the 
morphology of $T$. thaii and compared aspects of its morphology with the other members of the dalmanni species group. We have also performed an allometric analysis of $T$. thaii, with emphasis on its extreme sexual dimorphism, and compared its allometry to six other members of the Teleopsis genus.

\section{Method and materials}

All allometric and molecular work was performed on individuals taken from the same laboratory population as the morphologically described specimens.

\section{Allometric Comparisons}

T. thaii were reared in the laboratory under variable larval density to generate the variance in adult size required for the investigation of allometry (David et al. 1998, Cotton et al. 2004). Eclosing individuals (20 males and 25 females) were collected and measured to an accuracy of $0.01 \mathrm{~mm}$ using a monocular microscope and the image analysis program NIH Image (Version 1.55; National Institutes of Health, Bethesda, MD, USA). Measurements were taken of eye span (between the outermost lateral edges of the eye bulbs) and body length (from the front of the face to the tips of the wings; Baker \& Wilkinson 2001).

Absolute trait size data were non-normally distributed so differences between sexes were detected using non-parametric Wilcoxon-tests. Eye span is a highly allometric trait in stalk-eyed flies (Baker \& Wilkinson 2001), so we analysed sexual dimorphism of eye span using a General Linear Model (GLM) containing SEX and BODY LENGTH as fixed factors, their interaction, and an intercept. The significance of each effect (or interaction) was determined via $F$-tests on the change in explained variance upon removal of each term from the full model. A significant interaction implies that the relationship between eye span and body length (i.e. the allometric slope of eye span) differs between the sexes. We compared eyespan allometry and sexual dimorphism in T. thaii with that of its congeners using summary data published previously (Table 1 in Baker \& Wilkinson 2001).

TABLE 1. List of PCR primers.

\begin{tabular}{|c|c|c|c|}
\hline Gene & Sequence coordinate or primer name & Annealing temperature $\left({ }^{\circ} \mathrm{C}\right)$ & Reference \\
\hline $16 S$ & $\begin{array}{l}12727-12747(\mathrm{~S}) \\
13270-13290(\mathrm{~A})\end{array}$ & 50.0 & Baker et al. (2001) \\
\hline COII & $\begin{array}{l}\text { A3772 } \\
\text { S3291 }\end{array}$ & 50.8 & Brower (1994) \\
\hline$w$ & $\begin{array}{l}11404-11426(\mathrm{~S}) \\
11975-11997(\mathrm{~A})\end{array}$ & 58.6 & Baker et al. (2001) \\
\hline$w g$ & $\begin{array}{l}{ }^{5} \text { GTTAGAACATGTTGGATGCG }{ }^{3} \\
{ }^{5} \text { CGTTCAACGACAATGACCTC }{ }^{3,}\end{array}$ & 53.3 & Adapted from Baker et al. (2001) \\
\hline
\end{tabular}

Gene Cloning And Phylogenetic Analysis

Genomic DNA extractions, PCR and sequencing were performed using the protocol of Carr et al. (2006a). The primers used for 16 S ribosomal RNA (16S), cytochrome oxidase subunit II (COII), white (w) and wingless $(\mathrm{wg})$ are listed in Table 1.

The sequences for each of the genes have been deposited into the GenBank database (Accession numbers DQ191299-DQ191302). Phylogenies were created from each individual gene and, in addition, from a concatenated four-gene alignment.

The nucleotide sequences produced from $T$. thaii were aligned against the orthologous sequences from seven other Teleopsis, two Diopsis and one Eurydiopsis species taken from GenBank. Recent studies have 
shown that Diopsis and Eurydiopsis are closely related genera to Teleopsis (Baker et al. 2001) and therefore these sequences are appropriate to use to root the phylogenies of Teleopsis. Alignments were created using ClustalX (Thompson et al. 1997) and then edited by eye. Gaps present in coding regions were adjusted so that codons were maintained as intact. Both $w$ and $w g$ harbour introns in the regions amplified by PCR and these were retained in the alignments. However, both introns contained regions of low similarity possessing overlapping indels across the eleven species; these regions were excluded since they could not be unambiguously aligned.

The alignments were analysed with Modeltest 3.7 (Posada and Crandall 1998), which indicated that the General Time Reversible model (Rodríguez et al. 1990), with a designated proportion of invariant sites and a gamma correction for rate variation among sites $(\mathrm{GTR}+\mathrm{I}+\Gamma)$ was the most suitable nucleotide substitution model. In each of the analyses the gamma distribution was divided into four categories. Phylogenies were created using two likelihood methods, Bayesian Inference (BI) and Maximum Likelihood (ML). BI phylogenies were produced using MrBayes 3.1.1 (Ronquist \& Huelsenbeck 2003) and ML trees from Phyml 2.4.4 (Guindon \& Gascuel 2003). The parameters for each analysis were defined by the programs.

BI Monte Carlo Markov Chain analyses were performed with one cold and three hot chains, with a sample frequency of 10, until the two parallel runs had reached convergence (i.e. the average standard deviation of split frequencies $<0.01$ ). The first $25 \%$ of the sampled trees were discarded as burnin. ML trees were bootstrapped with 1000 replicates. The alignments used to produce the phylogenies are available from the authors upon request.

\section{Teleopsis thaii Földvári \& Carr, new species}

(Figs 1-5)

Teleopsis sp. n.: Carr et al. 2006b, Carr 2007

Teleopsis sp. n. 1: Papp et al. 2006

Diagnosis: Inner vertical bristle (IVB) only 3-4 times as long as the width of eye stalks in the middle. Thorax shiny in general, scutellar spines up to 5 times as long as scutellum (longest among this four species group). Epandrium in dorsal view narrower than hypandrium. Only few hairs (8-10) at the base of hypandrium. Hypandrial bridge broad, widest at the middle.

Type material: Holotype, male (Hungarian Natural History Museum, Budapest). Paratypes 4 males, 5 females (Hungarian Natural History Museum, Budapest), 5 males, 5 females (Natural History Museum, London). All type specimens (dried, double mounted, excellent condition) taken from a laboratory culture housed at University College, London in July 2006. Parent specimens were collected at Doi Suthep National Park, Chiang Mai, Thailand. Label data: over and along a brook, above and below a small waterfall, Nov 9, 2004, leg. L. Papp \& M. Földvári, No. 27.

Head: Yellowish red, with minute, whitish hairs, up to 1.5 times the width of eye stalks in the middle. No facial teeth, edges rounded. Outer vertical bristle (OVB) narrow, 1.5 times the width of eye stalks in the middle. IVB on a small tubercle black, 3-4 times the width of eye stalks in the middle.

Thorax: Generally shiny, Intra-alar spine (IAS) yellow, slightly curved posteriorly in dorsal view, flattened dorsoventrally. Scutellar spine up to 5 times longer than scutellum, yellow-brown, with hairs on the spine as long as the diameter of the spine.

Wing: Four dark bands, proximal band pale, only a dark spot visible above cell cup.

Legs: Covered with hairs (shorter than those on the head). Coxae and femora yellow, tibiae and tarsi brown, front femora with rows of peg-like black tubercles; mid femora slightly swollen in posterior view. 
Praeabdomen: Tergites 1 and 2 completely yellow, first half of tergite 3 yellow, otherwise brown. Tergites 1 and 2 with brown spots dorsally in the middle; tergite 3 with grey pollinose spots on the sides. Hairs on the abdomen (as well as all over the body) moderately long, up to $1 / 2$ of the length of the first coxa

Genitalia: The epandrium and the cerci have long, dispersed setae along their surface. There are two hairs and four minute setae at the base of the hypandrium, the tip of the surstyli have numerous short, distinct hairs (Fig. 2). In lateral view the aedeagal apodeme is slightly curved, longest among the four species discussed here, not broadening towards tip (Fig. 3). The parameres in ventral view have two long and two minute hairs (Fig. 4). The hypandrium is connected to the aedeagal apodeme and the membranous tip of the hypandrium (hypandrial bridge) is continuous, not divided into two lobes anteriorly (Fig. 5). The genitalia in ventral view are broader at the membranous part of the hypandrium than at the surstyli, i.e. the epandrium (Fig. 4).

Etymology: The name refers to Thailand where the type locality can be found.

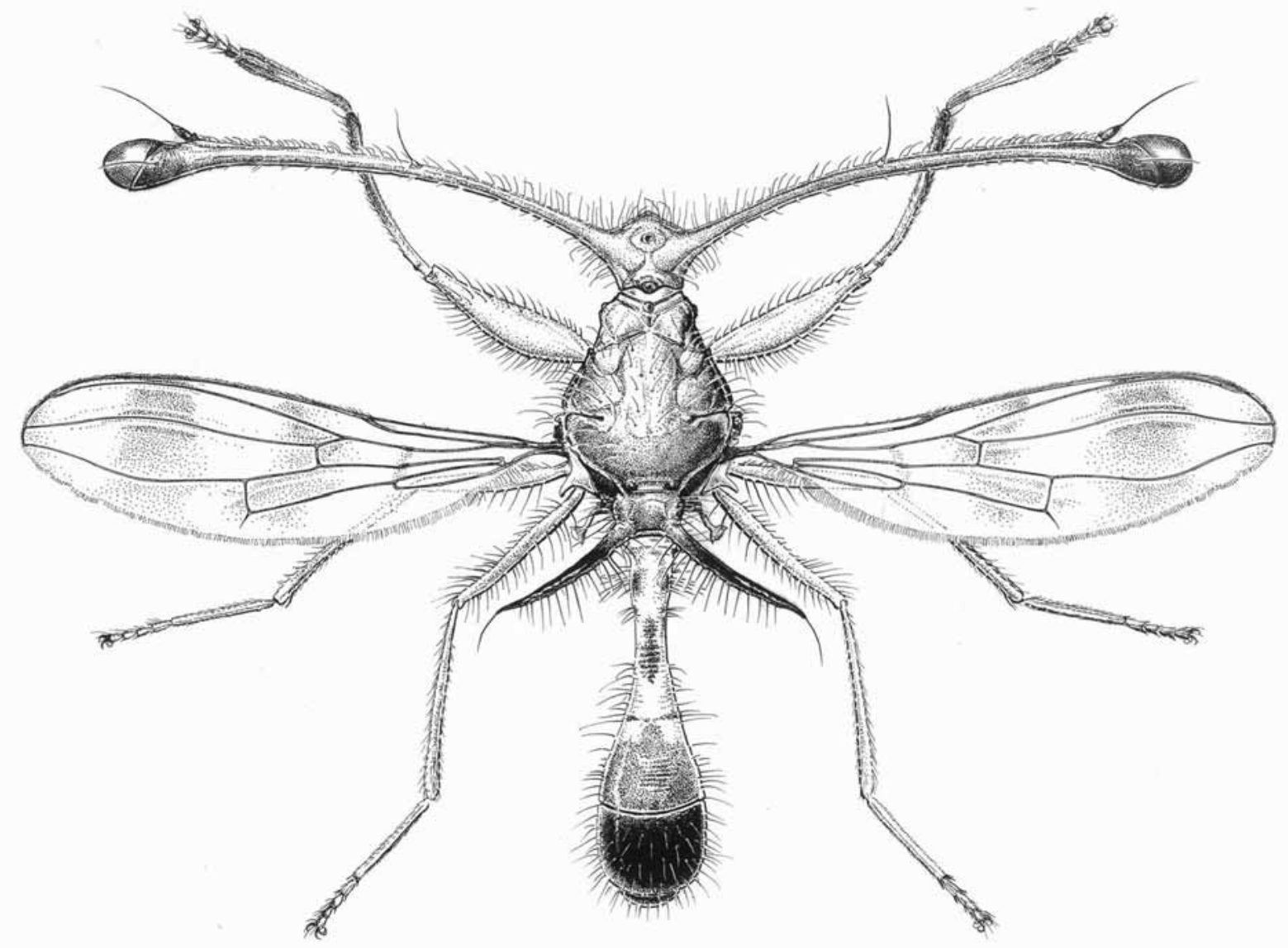

FIGURE 1. $T$. thaii, habitus, specimen collected at the type locality.

Teleopsis whitei (Curran, 1936)

(Figs 6-9)

Diopsis whitei Curran 1936: 1.

Diagnosis: IVB length up to 4.5 times as long as width of eye stalk in the middle. Thorax pollinose on posterior part, scutellar spines up to 3.5 times as long as length of scutellum. Epandrium in dorsal view as wide as hypandrium. Only few hairs (4-6) at the base of hypandrium. Hypandrial bridge broad, slightly narrowed at the middle. 

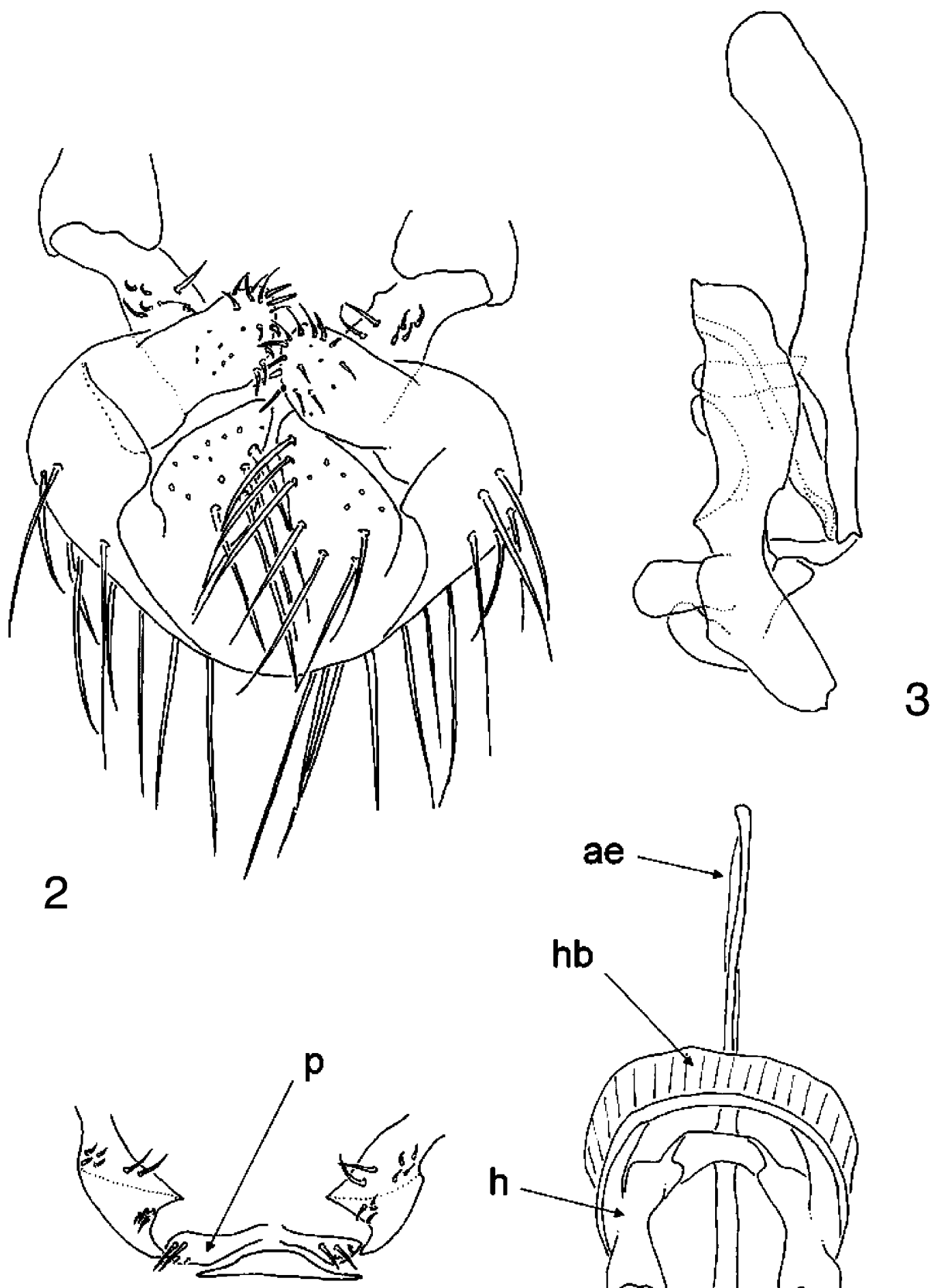

4
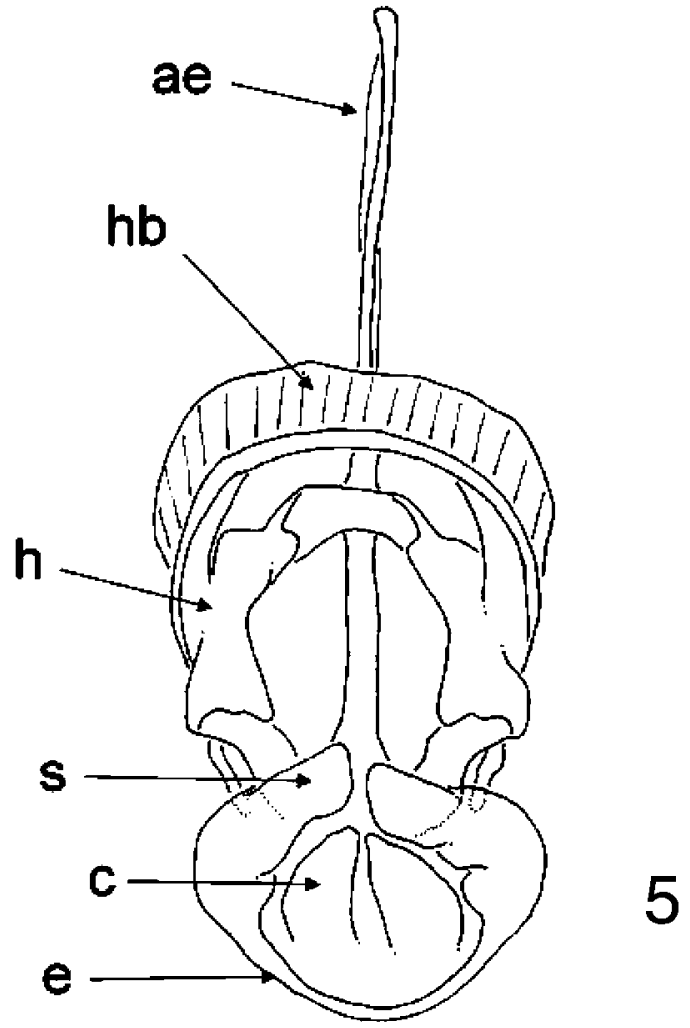

FIGURES 2-5. T. thaii sp. n. male genitalia. 1: detailed ventral view with surstyli, gonopods, cerci, 2: lateral view with aedeagal apodeme, hypandrium and epandrium, 3: detailed ventral view with base of hypandrium and parameres, 4: ventral view. Legend: ae: aedeagal apodeme, c: circus, e:epandrium, h: hypandrium, hb: hypandrial bridge, p: paramere, s: surstylus. 

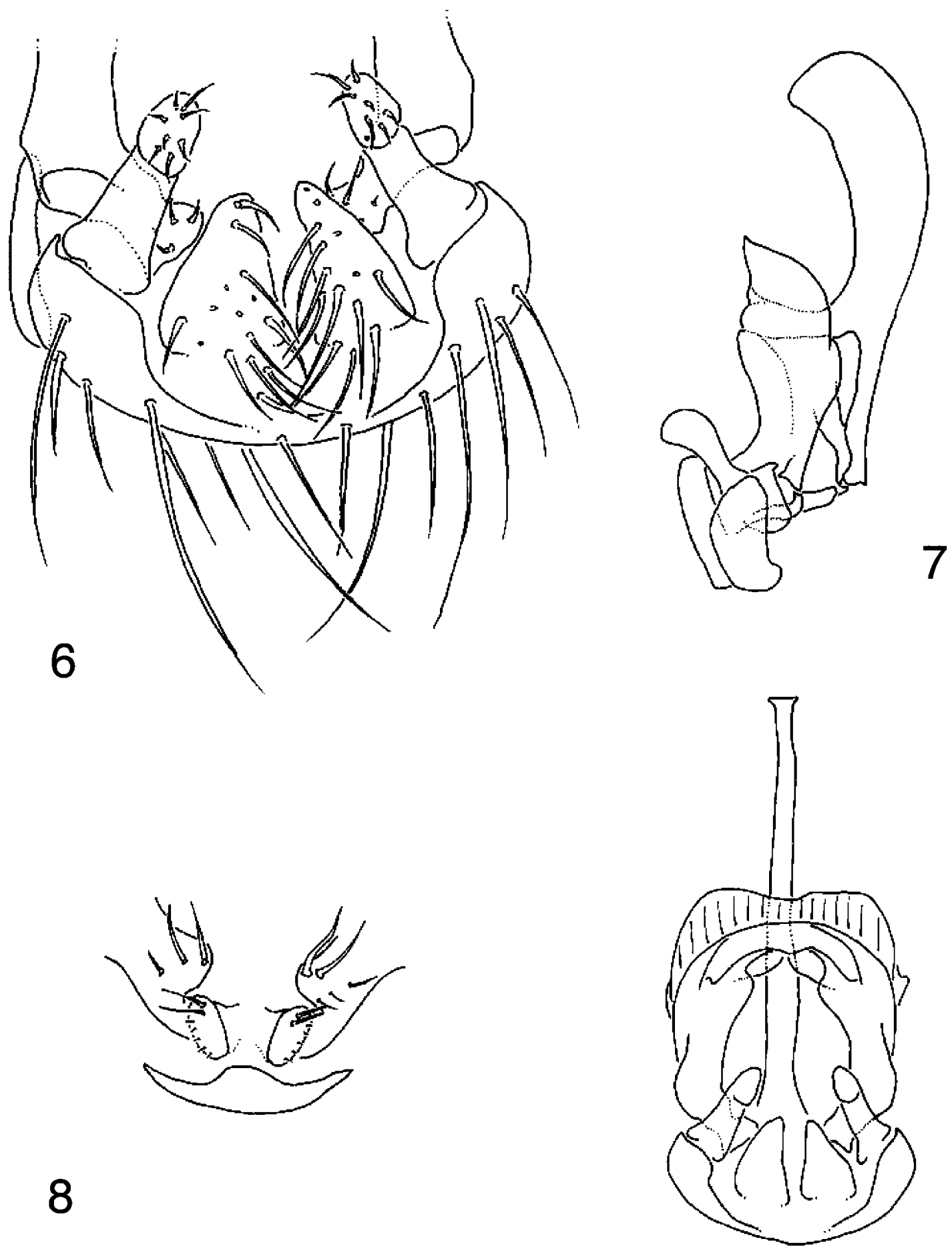

9

FIGURES 6-9. T. whitei male genitalia. 5: detailed ventral view with surstyli, gonopods, cerci, 6: lateral view with aedeagal apodeme, hypandrium and epandrium, 7: detailed ventral view with base of hypandrium and parameres, 8: ventral view.

Material examined: 5 males, 5 females taken from a laboratory culture housed at University College, London in July, 2006. This culture was founded from individuals caught in Ulu Gombak, Malaysia by Andrew Pomiankowski and Samuel Cotton in April 2005. The dried, double-mounted specimens are deposited in the Hungarian Natural History Museum, Budapest.

Head: Yellow-brown, covered with white hairs up to as long as width of eye-stalk in the middle. No facial teeth, face rounded at the edges. OVB black, slightly larger than width of eye-stalk in the middle. IVB on a 
small tubercle in the middle of eye stalk. IVB length up to 4.5 times as long as width of eye-stalk in the middle.

Thorax: Shiny yellow-brown on sides, anepimeron and posterior half of meron grayish pollinose. Scutum somewhat golden pollinose. IAS yellow, flattened dorsoventrally. Scutellar spines up to 3.5 times as long as length of scutellum.

Wing: Hyaline with 4 bands; proximal and distal bands are narrow and pale, $2^{\text {nd }}$ band includes distal part of cell $\mathrm{dm}$ and $\mathrm{R}-\mathrm{M}$ cross vein; $3^{\text {rd }}$ band attaches to the $2^{\text {nd }}$ along vein $\mathrm{M}$.

Legs: Covered with hairs (shorter than those on the head). Coxae and femora yellow, tibiae and tarsi brown, front femora with rows of peg-like black tubercles.

Praeabdomen: Covered with hairs (shorter than those on the head). Tergites generally brown with yellow stripe on front half of $\mathrm{T} 3$ and sides of T1-3.

Genitalia: The epandrium and the cerci have long, dispersed setae along their surface. There are two hairs (longer than T. thaii) and two minute setae at the base of the hypandrium, the tip of the surstyli have numerous short, distinct hairs, surstyli broadened at tip (Fig. 6). In lateral view the aedeagal apodeme is curved (more than that of $T$. thaii), broad at distal one third (Fig. 7). The parameres in ventral view have two long and 4-6 minute hairs (Fig. 8). The hypandrium is connected to the aedeagal apodeme and the membranous tip of the hypandrium (hypandrial bridge) is slightly divided into two parts anteriorly (Fig. 9). The genitalia in ventral view are as broad at the membranous part of the hypandrium as at the surstyli, i.e. the epandrium (Fig. 9).

\section{Teleopsis dalmanni (Wiedemann, 1830)}

(Figs 10-13)

Diopsis dalmanni Wiedemann 1830: 560.

Diagnosis: The most densely haired among the four species, front femur apically strongly incrassate, mid femur distally swollen. IVB up to 4-5 times as long as width of eye stalk in the middle, scutellar spines up to 4 times as long as length of scutellum. Epandrium in dorsal view wider than hypandrium. Two thick setae at the base of hypandrium. Hypandrial bridge broad and with incision at the middle.

Material examined: 5 males, 5 females taken from a laboratory culture housed at University College, London in July, 2006. This culture was founded from individuals caught in Ulu Gombak, Malaysia by Andrew Pomiankowski and Samuel Cotton in April 2005. The dried, double-mounted specimens are deposited in Hungarian Natural History Museum, Budapest.

Head: Yellow-brown, covered with brown hairs up to 3 times as long as width of eye-stalk in the middle. No facial teeth, edge rounded. OVB black twice as long as width of eye-stalk in the middle. IVB up to 4.5-5 times as long as width of eye-stalk in the middle; on a small tubercle.

Thorax: Shiny yellow, without pollinosity. Intra-alar spine (IAS) yellow, dorsoventrally flattened, blunt in dorsal view. Scutellar spines up to 4 times as long as length of scutellum.

Wing: Hyaline with only 3 bands (distal fourth is missing). Proximal band continuing in the area of the cell cup, $2^{\text {nd }}$ band includes distal part of cell $\mathrm{dm}$ and R-M cross vein; $3^{\text {rd }}$ band attaches to the $2^{\text {nd }}$ along vein $\mathrm{M}$.

Legs: Covered with hairs (shorter than those on the head). Coxae and femora yellow, tibiae and tarsi brown, front femora with rows of peg-like black tubercles. Front femur apically strongly incrassate, mid femur distally swollen (best seen in posterior view). Distal 2/5 of the first tarsus broad, dark brown to black ventrally on the front leg.

Praeabdomen: Tergites 1 and 2 completely yellow, first half of tergite 3 yellow, otherwise brown. Tergites 1 and 2 with brown spots dorsally in the middle; tergite 3 with grey pollinose spots on the sides. Hairs on the abdomen (as well as all over the body) very long, up to the length of the first coxa. 

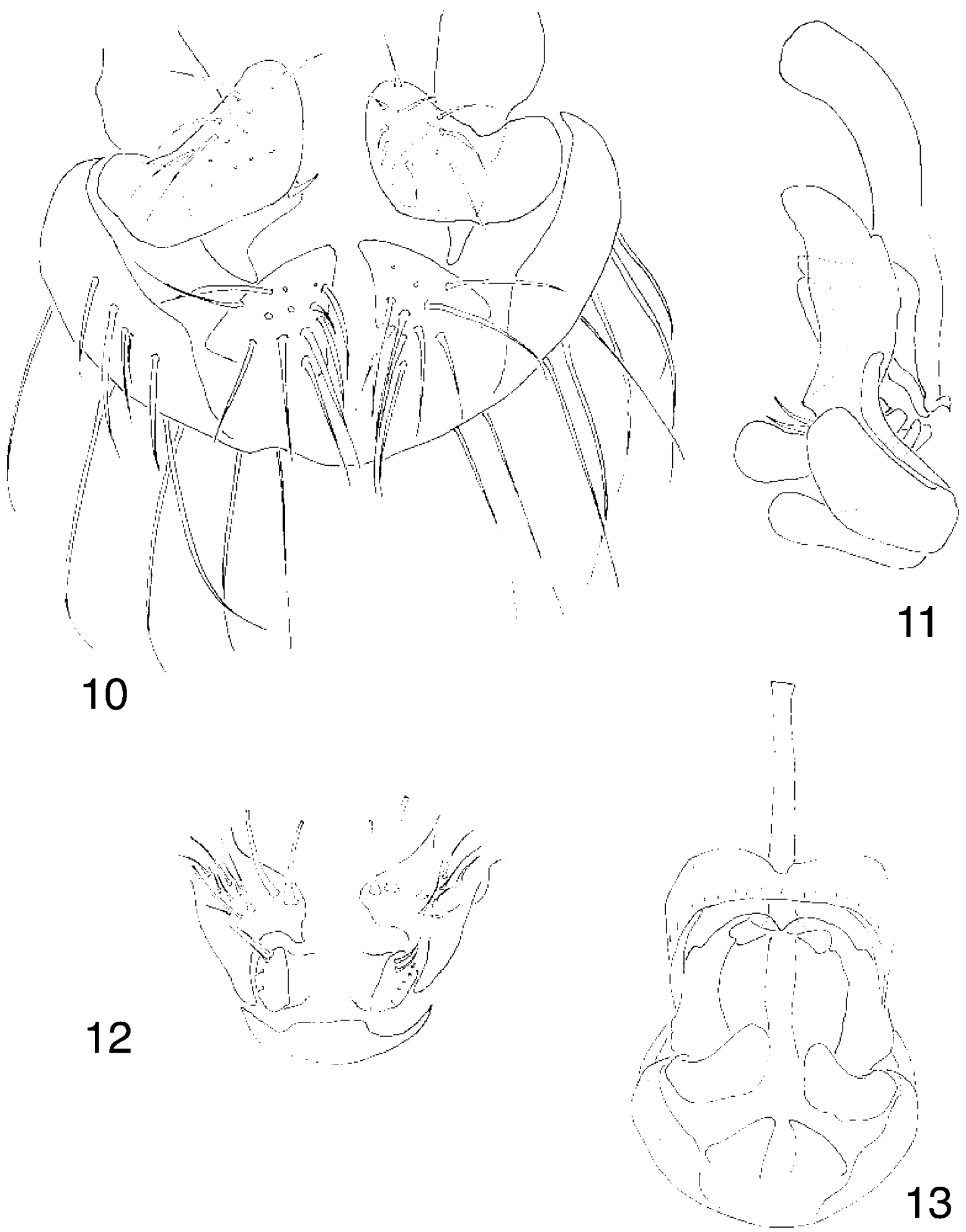

FIGURES 10-13. T. dalmanni male genitalia. 9: detailed ventral view with surstyli, gonopods, cerci, 10: lateral view with aedeagal apodeme, hypandrium and epandrium, 11: detailed ventral view with base of hypandrium and parameres, 12: ventral view.

Genitalia: The epandrium and the cerci have long, dispersed setae along their surface. There are two thick setae and 7-10 long hairs at the base of the hypandrium, the tip of the surstyli have numerous longer hairs, more dispersed than T. thaii and T. whitei). Surstyli broad in general, broadest among the four species (Fig. 
10). In lateral view the aedeagal apodeme is curved (as in $T$. whitei), not broadened at distal one third (Fig. 11). The parameres in ventral view have two long and 2-4 minute hairs (Fig. 12). The hypandrium is connected to the aedeagal apodeme and the membranous tip of the hypandrium (hypandrial bridge) is clearly divided into two parts anteriorly by an incision (Fig. 13). The genitalia in ventral view are narrower at the membranous part of the hypandrium than at the surstyli, i.e. the epandrium (Fig. 13).

\section{Teleopsis currani (Shillito, 1940)}

(Figs 14-17)

Cyrtodiopsis currani Shillito 1940: 159.

Diagnosis: IVB on large protuberance, that is up to $3 / 4$ of the width of eye stalk in the middle, length of IVB $4-$ 5 times as long as eye stalk in the middle. OVB: 3-4 times the width of eye stalks in the middle (much longer than in other species), IAS not flattened (unlike in other three species). Scutellar spines 3-3.5 times as long as length of scutellum. Epandrium in dorsal view as wide as hypandrium. Only few hairs (8-10) at the base of hypandrium. Hypandrial bridge narrow.

Material examined: 2 males, 2 females, Thailand, Bangkok, 1-7 March 1971, [leg.] P. \& P. Spangler (National Museum of Natural History, Washington D.C.)

Head: Yellow-brown, covered with minute whitish hairs up to $1 / 2$ of the width of eye stalk in the middle. No facial teeth, edge rounded. OVB black, 3-4 times as long as width of eye stalk in the middle. IVB on large protuberance, that is up to $3 / 4$ of the width of eye stalk in the middle, length of IVB $4-5$ times as long as eye stalk in the middle.

Thorax: Shiny yellow-brown, pollinosity only on the sides, posteriorly. IAS yellow-brown, not flattened. Scutellar spines 3-3.5 times as long as length of scutellum, darker towards tip.

Wing; Four dark bands (appearing as a dark wing with 3 white bands). The second dark band is continuous with the third, 3 white spots in the middle of the wing (border of the two dark bands).

Legs: Covered with hairs (shorter than those on the head). Coxae and femora yellow, tibiae and tarsi brown, front femora with rows of peg-like black tubercles. Front femora similar to those of $T$. whitei, but shorter.

Praeabdomen: Tergites 1 and 2 yellow, otherwise brown, anterior part of tergite 2 brown, tergite 4 grayish pollinose. Hairs dispersed, short, the longest up to $1 / 3$ of the length of first coxa.

Genitalia: The epandrium and the cerci have long, dispersed setae along their surface. There are two hairs (as long as T. whitei) and 6-8 minute setae at the base of the hypandrium, the tip of the surstyli have numerous longer hairs, more dispersed than T. thaii and T. whitei), i.e. not restricted to the tip. Surstyli slightly broadened in apical part (Fig. 14). In lateral view the aedeagal apodeme is curved (as in T. thaii), broadest in the middle (Fig. 15). The parameres in ventral view have two long and 2-4 minute hairs (Fig. 16). The hypandrium is connected to the aedeagal apodeme and there is no membranous part of the hypandrium, the hypandrial bridge is narrow (Fig. 17). The genitalia in ventral view are as broad at the membranous part of the hypandrium as at the surstyli, i.e. the epandrium, comparable to T. whitei (Fig. 17).

\section{Allometry of Teleopsis thaii}

Male T. thaii were significantly larger than females for both eyespan and body length (Fig. 18; Table 2; $\chi^{2}=$ 25.02, d.f. $=1, P<0.001$ and $\chi^{2}=7.52$, d.f. $=1, P=0.006$, respectively). There was significant difference in the slope of eyespan allometry between male and female $T$. thaii, with males having a steeper scaling relationship (Fig. 18; SEX $\times$ BODY LENGTH interaction term in Table 3). 

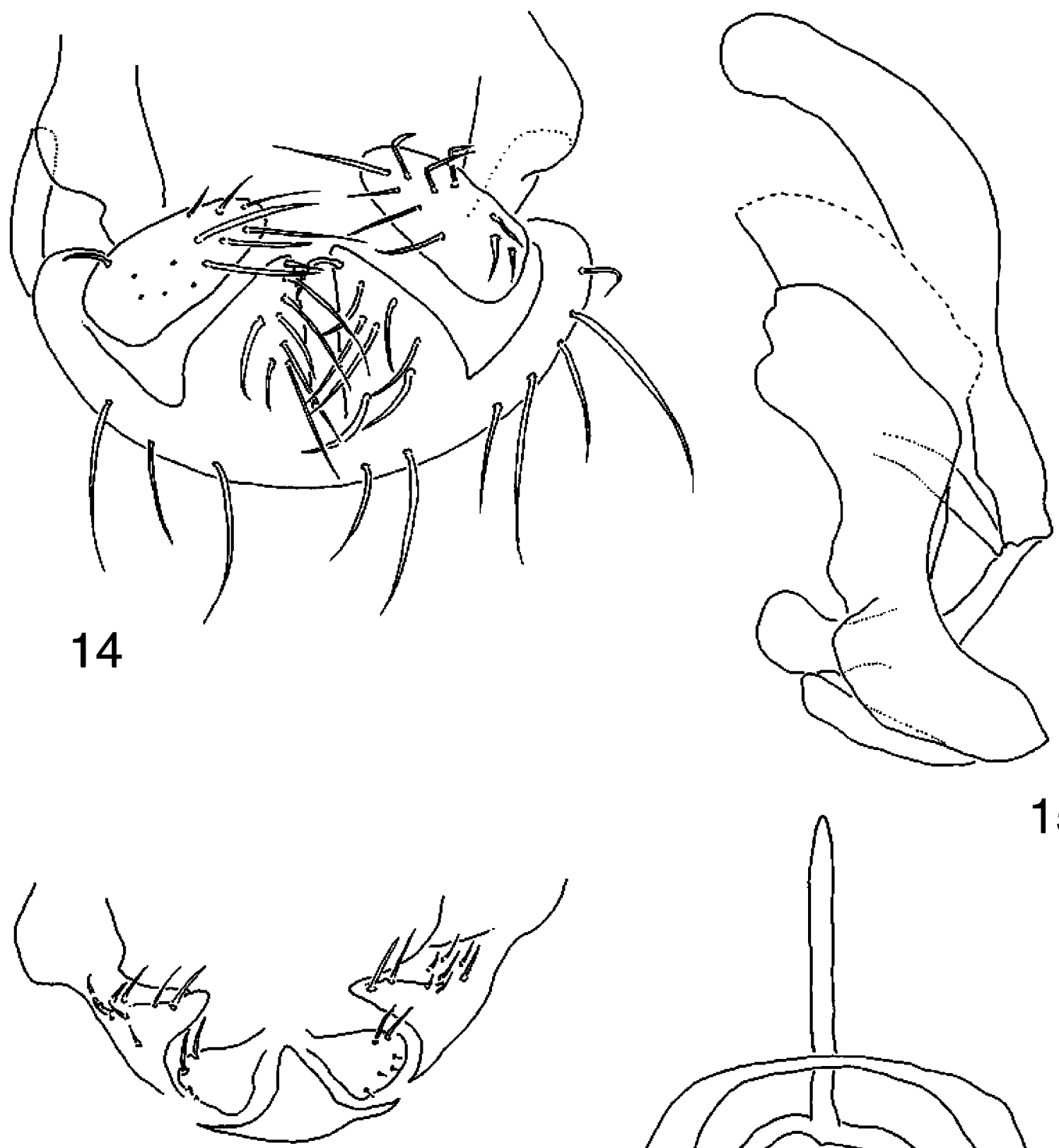

16

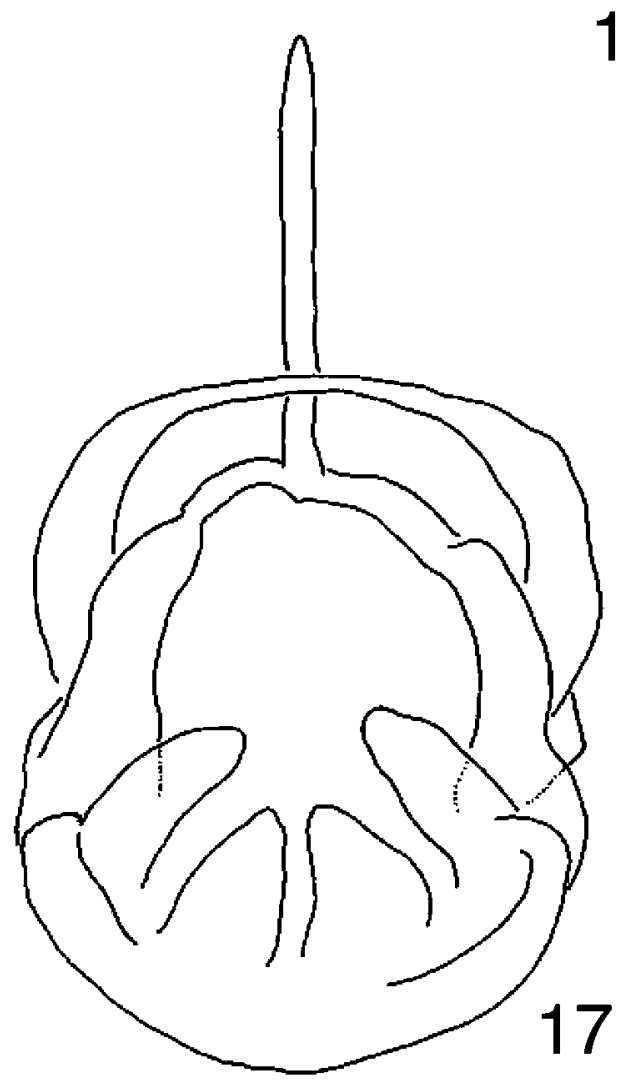

FIGURES 14-17. T. currani male genitalia. 13: detailed ventral view with surstyli, gonopods, cerci, 14: lateral view with aedeagal apodeme, hypandrium and epandrium, 15: detailed ventral view with base of hypandrium and parameres, 16: ventral view. 
Male T. thaii have the largest mean eyespan of all the species available for phylogenetic and morphological comparisons (Table 2). In addition, the slope of male eyespan allometry and the degree of sexual dimorphism observed in T. thaii is greater than that of all other recorded species except T. breviscopium (Table 2).

TABLE 2. Mean trait size (mm) for eyespan (ES), body length (BL) and allometric slope ( \pm S.E.) of male and female $T$. thaii $(N=$ sample size). Allometric slope is the least-squares regression coefficient of eyespan on body length. Sexual dimorphism is computed as the difference between male and female slopes. For comparison, the same metrics are given for other members of the Teleopsis genus (data from Baker \& Wilkinson 2001).

\begin{tabular}{|c|c|c|c|c|c|c|c|c|c|}
\hline \multirow[t]{2}{*}{ Species } & \multicolumn{4}{|c|}{ Males } & \multicolumn{4}{|c|}{ Females } & \multirow{2}{*}{$\begin{array}{l}\text { Sexual } \\
\text { dimor- } \\
\text { phism }\end{array}$} \\
\hline & $N$ & Mean ES & Mean BL & $\begin{array}{l}\text { Allometric } \\
\text { slope }\end{array}$ & $N$ & Mean ES & Mean BL & $\begin{array}{l}\text { Allometric } \\
\text { slope }\end{array}$ & \\
\hline T. thaii & 20 & 11.18 & 8.03 & $2.50 \pm 0.13$ & 25 & 6.86 & 7.46 & $0.97 \pm 0.05$ & 1.531 \\
\hline T. dalmanni & 93 & 7.49 & 6.23 & $2.31 \pm 0.07$ & 91 & 5.20 & 5.86 & $1.14 \pm 0.03$ & 1.168 \\
\hline T. quinqueguttata & 102 & 4.26 & 6.97 & $0.69 \pm 0.03$ & 66 & 4.28 & 7.15 & $0.67 \pm 0.04$ & 0.024 \\
\hline T. whitei & 86 & 7.97 & 6.37 & $2.13 \pm 0.05$ & 86 & 4.67 & 5.55 & $1.12 \pm 0.02$ & 1.006 \\
\hline T. breviscopium & 60 & 10.98 & 6.32 & $2.73 \pm 0.30$ & 30 & 6.09 & 6.38 & $0.95 \pm 0.11$ & 1.779 \\
\hline T. quadriguttata & 29 & 3.33 & 4.98 & $0.71 \pm 0.04$ & 18 & 3.37 & 5.21 & $0.63 \pm 0.04$ & 0.084 \\
\hline T. rubicunda & 89 & 4.97 & 4.92 & $1.73 \pm 0.08$ & 52 & 4.65 & 5.45 & $1.15 \pm 0.05$ & 0.579 \\
\hline
\end{tabular}

TABLE 3. General Linear Model of body length and sex effects on eyespan in T. thaii.

\begin{tabular}{llllll}
\hline Factor & SS & d.f. & MS & $F$-ratio & Prob $>F$ \\
\hline body length & 191.79 & 1 & 191.79 & 1892.67 & $<0.001$ \\
sex & 91.95 & 1 & 91.95 & 907.40 & $<0.001$ \\
sex $\times$ body length & 9.09 & 1 & 9.09 & 89.75 & $<0.001$ \\
error & 4.15 & 41 & 0.10 & & \\
Total & 292.83 & 44 & & & \\
\hline
\end{tabular}

\section{Gene sequencing and phylogenetic analysis}

Two likelihood methods were employed to create phylogenies for each of the four genes (data not shown). None of the single gene phylogenies showed strong support for the position of $T$. thaii, however seven out of the eight trees group T. thaii with T. currani, T. dalmanni and $T$. whitei. This four species group is robustly supported for the two nuclear protein-encoding genes (BI posterior probability=1.00, ML bootstrap support=100\%), but only with weak support in the $16 S$ and Bayesian COII trees.

A concatenated four-gene alignment was constructed and in both the Bayesian and ML phylogenies the four species clade was recovered (see Figure 19). None of the internal branches in the concatenated phylogenies showed strong support (i.e. BI posterior probability $\geq 0.97$, ML bootstrap support $\geq 75 \%$ ) in the species group, however weak support was given for T. thaii being the sister-species to T. dalmanni + T. whitei.

\section{Comments}

Morphologically the genitalia of the four species are very similar and there are small differences to separate them. Based on the shape of the different parts the species can be aligned in a row of gradual change. Accord- 
ing to the shape in ventral view: T. thaii - T. currani-T. whitei-T. dalmanni from the narrowest to the broadest epandrium compared to the width of the hypandrium (Figs 4, 8, 12,16). According to the shape of the aedeagal apodeme: T. thaii $-T$. currani $-T$. dalmanni $-T$. whitei from the longest and narrowest to the most curved and broadest (Figs 2, 6, 10, 14). According to the shape of the surstylus: T. whitei - T. currani $-T$. thaii $-T$. dalmanni from the narrowest to the broadest (Figs 2, 6, 10, 14). It is not known whether these characters contain phylogenetic information, only a detailed morphological study of features in numerous populations would allow us to draw the conclusions.

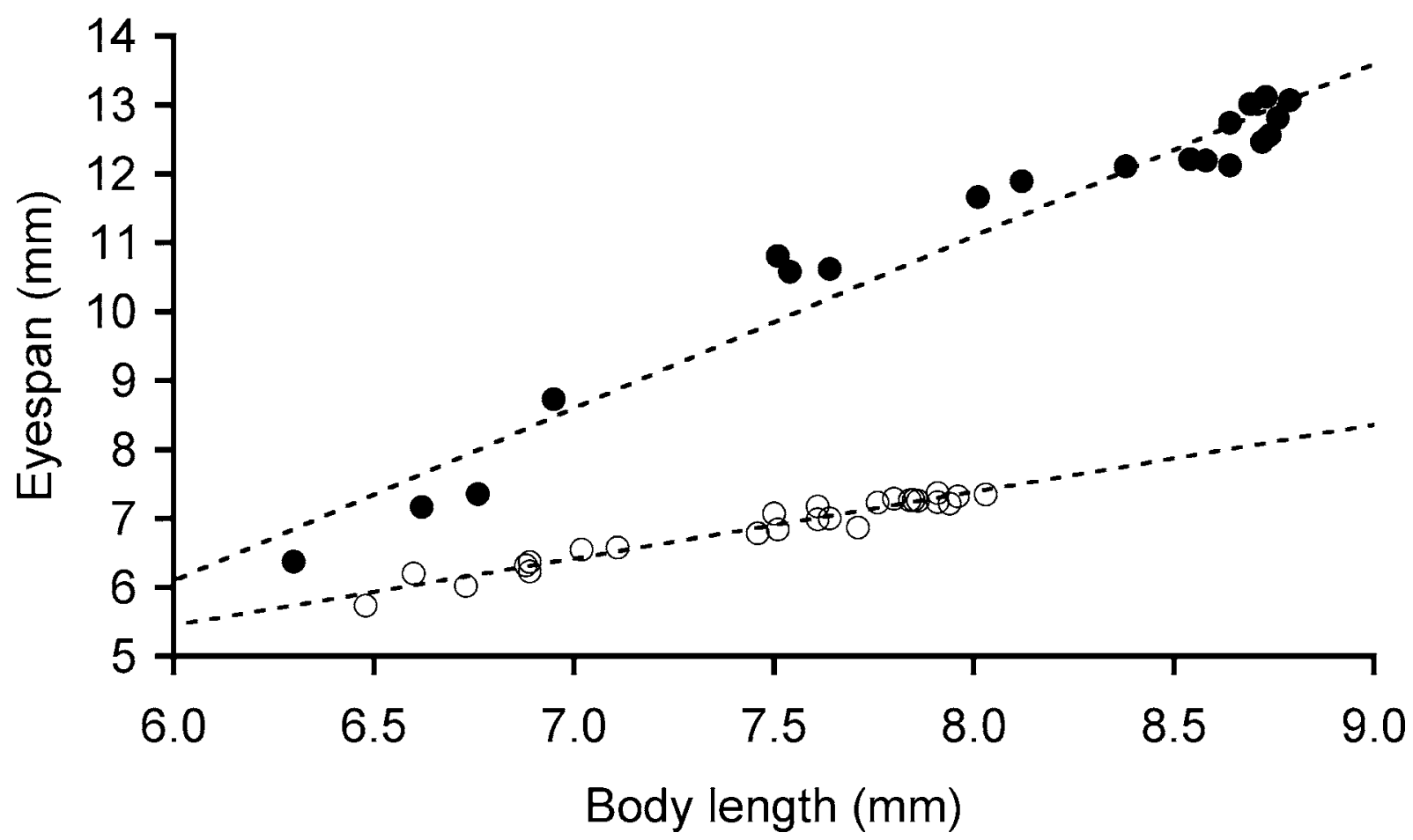

FIGURE 18. Eyespan allometry in $T$. thaii. Males $=$ closed circles, females $=$ open circles. Least-squares regression lines are given for heuristic purposes.

Genetic data gave different results, since partial sequences from four genes, analysed as individual and concatenated alignments, failed to confidently place $T$. thaii within the Teleopsis genus. A consistent result in the phylogenies produced was a clade made up of T. currani, T. dalmanni, T. thaii and T. whitei. We have termed this clade the dalmanni species group (named after the first species in the group to be described).

The concatenated dataset weakly place T. thaii as the outgroup to T. dalmanni and T. whitei. Within all of the trees the dalmanni species group shows short internal branches and long terminal branches suggesting, irrespective of the branching order, all species in the group diverged rapidly.

There are a number of possible, not mutually exclusive, explanations for the lack of resolution within the species group. A rapid radiation of the four species is likely to have produced little phylogenetic signal and any trace of this signal may have been swamped by mutations that have occurred on the long terminal branches. It is also possible that ancestral polymorphisms may have segregated unevenly amongst the lineages resulting in a "noisy" phylogeny. A third explanation could be limited gene flow between the four closely related species, which could produce the incongruencies observed between the different gene phylogenies. Given the apparent rapid radiation of the dalmanni species group, highlighted by the four genes sequenced here, it may not be possible to robustly determine the phylogenetic position of $T$. thaii without the sequencing of a large number of informative genes in all four member species.

T. thaii are, on average, larger than the other Teleopsis species presented here for both eyespan and body length. Such differences do not result from simple changes in scale, as eyespan in T. thaii also has a much 
steeper male (but not female) allometric slope and hence shows much greater sexual dimorphism than those of other members of the dalmanni species group. It is likely that such morphological differences have resulted from current or past episodes of sexual selection for increased male eyespan, as all sexually-selected diopsids studied thus far exhibit an elevated male eye span allometry (Burkhardt \& de la Motte 1985; Wilkinson \& Dodson 1997; Baker \& Wilkinson 2001; Cotton et al. 2006). However, without additional experiments this hypothesis cannot be tested.

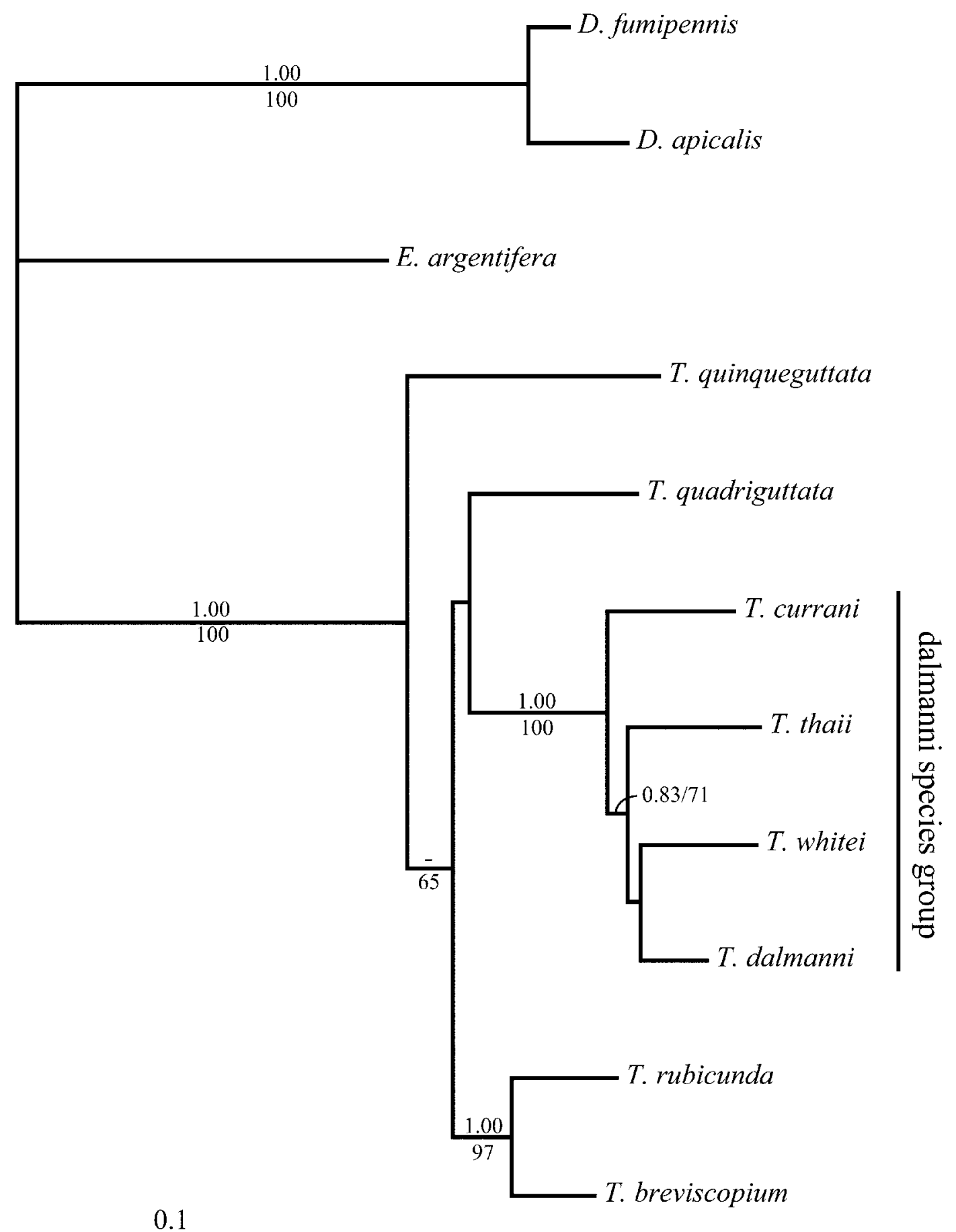

\section{$16 S+w+w g+C O I I$}

FIGURE 19. Bayesian phylogeny of the Teleopsis genus created using $16 S+w+w g+C O I I$. Bayes Posterior Probabilities and Maximum Likelihood Bootstrap Support values are given above and below each branch respectively. Unsupported branches are unlabeled, Posterior Probabilities values below 0.70 and Bootstrap Support values below 50\% are represented by "-". The bar represents the number of nucleotide substitutions per site. 
Male eyespan allometry and sexual dimorphism in $T$. thaii is not as pronounced as that reported for its congener, T. breviscopium. However, given that $T$. thaii and $T$. breviscopium are quite distantly related within the Teleopsis genus, the most parsimonious explanation for the existence of the large eyespan seen in T. thaii is that of independent evolution. The alternative hypothesis, that the large eyespans seen in these species are the result of a single evolutionary event in a common ancestor, is unlikely, as it requires a large number of reductions in eyespan size, scaling relationships and sexual dimorphism across the rest of the Teleopsis phylogeny.

\section{Acknowledgements}

Many thanks go to Sandie Baldauf for providing laboratory facilities during the completion of this work. We are grateful to Albert Szappanos for producing the T. thaii habitus image. We are also grateful to Prof. Jarujin Nabhitabhata (National Science Museum, Thailand), for his help, information and advice he gave us during the field work in 2004 sponsored by the Hungarian Scientific Research Found (OTKA, T 042540), and we are grateful to the grant OTKA F 048857 for support of open access of this publication. We thank two reviewers for providing useful remarks on the manuscript.

\section{References}

Baker, R.H. \& Wilkinson, G. (2001) Phylogenetic analysis of sexual dimorphism and eye-span allometry in stalk-eyed flies (Diopsidae). Evolution, 55, 1373-1385.

Baker, R.H., Wilkinson, G. \& DeSalle, R. (2001) Phylogenetic utility of different types of molecular data used to infer evolutionary relationships among stalk-eyed flies (Diopsidae). Systematic Biology, 50, 87-105.

Brower, A.V.Z. (1994) Phylogeny of Heliconius butterflies inferred from mitochondrial DNA sequences (Lepidoptera: Nymphalidae). Molecular Phylogenetics and Evolution, 3, 159-174.

Burkhardt, D. \& de la Motte, I. (1985) Selective pressures, variability, and sexual dimorphism in stalk-eyed flies (Diopsidae). Naturwissenschaften 72, 204-206.

Carr, M. (2007) Multiple subfamilies of mariner transposable elements are present in stalk-eyed flies (Diptera: Diopsidae). Genetica, in press (DOI : 10.1007/s10709-007-9157-2.).

Carr, M., Cotton, S., Földvári, M. \& Kotrba, M. (2006a) A description of a new species of Diasemopsis (Diptera, Diopsidae) from the Comoro Islands with morphological, molecular and allometric data. Zootaxa, 1211, 1-19.

Carr, M., Cotton, S., Rogers, D.W., Pomiankowski, A., Smith, H. \& Fowler, K. (2006b) Assigning sex to pre-adult stalkeyed flies using genital disc morphology and $X$ chromosome zygosity. BMC Developmental Biology, 6, 29.

Cotton, S., Folwer, K. \& Pomiankowski, A. (2004) Condition-dependence of sexual ornament size and variation in the stalk-eyed fly Cyrtodiopsis dalmanni (Diptera: Diopsidae). Evolution, 58, 1038-1046.

Cotton, S., Rogers, D.W., Small, J., Pomiankowski, A. \& Fowler, K. (2006) Variation in preference for a male ornament is positively associated with female eyespan in the stalk-eyed fly Diasemopsis meigenii. Proceedings of the Royal Society London B. 273, 1287-92.

Curran, C.H. (1936) A new Diopsis from India, with notes on others (Diptera). American Museum Novitates, 833, 1-2.

David, P., Hingle, A., Greig, D., Rutherford, A., Pomiankowski, A. \& Fowler, K. (1998). Male sexual ornament size but not asymmetry reflects condition in stalk-eyed flies. Proceedings of the Royal Society. B., 265, 2211-2216.

Feijen, H.R. (1998) Teleopsis Rondani (Diptera, Diopsidae): Generic review and the Ferruginea group from Sri Lanka. Tijdschrift voor Entomologie, 141, 49-63

Feijen, H.R. (1999) A revision of Eurydiopsis Frey (Diptera, Diopsidae) with description of four new Oriental species. Tijdschrift voor Entomologie, 141, 221-240.

Guindon, S. \& Gascuel, O. (2003) A simple, fast, and accurate algorithm to estimate large phylogenies by maximum likelihood. Systematic Biology, 52, 696-704.

Hingle, A., Fowler, K. \& Pomiankowski, A. (2001) Size-dependent mate preference in the stalk-eyed fly Cyrtodiopsis dalmanni. Animal Behaviour, 61, 589-595.

Kotrba, M. \& Balke, M. (2006) The systematic position of Cladodiopsis Séguy, 1949 and the origin of sexual dimorphism in stalk-eyed flies (Diptera: Diopsidae) inferred from DNA sequence data. Molecular Phylogenetics and Evolution, 38, 843-847. 
Meier, R. \& Baker, R.H. (2002) A cladistic analysis of Diopsidae (Diptera) based on morphological and DNA sequence data. Insect Systematics and Evolution, 33, 325-336.

Papp, L., Földvári, M. \& Paulovics, P. (1997) Sphyracephala europaea sp. n. (Diptera: Diopsidae) from Hungary represents a family new to Europe. Folia Entomologica Hungarica, 58, 137-146.

Papp, L., Merz, M. \& Földvári, M. (2006) Diptera of Thailand. A summary of the families and genera with references to the species representations. Acta zoologica Academiae Scientiarum hungaricae, 52, 97-269.

Posada, D. \& Crandall, K.A. (1998) Modeltest: testing the model of DNA substitution. Bioinformatics, 9, 817-818.

Rodríguez, F, Oliver, JL, Marín, A \& Medina, JR (1990) The general stochastic model of nucleotide substitution. Journal of Theoretical Biology, 142, 485-501.

Ronquist, F. \& Huelsenbeck, J.P. (2003) MrBayes 3: Bayesian phylogenetic inference under mixed models. Bioinformatics B, 19, 1572-1574.

Shillito, J.F. (1940) Studies on Diopsidae (Diptera) Novitates Zoologicae, 42, 147-163.

Swofford, D.L. (2002) PAUP*. Phylogenetic analysis using parsimony (*and other methods). Version 4. Sinauer Associates, Sunderland, Massachusetts, USA.

Thompson, J.D., Gibson, T.J., Plewniak, F., Jeanmougin, F. \& Higgins, D.G. (1997) The CLUSTAL_X windows interface: flexible strategies for multiple sequence alignment aided by quality analysis tools. Nucleic Acids Research, 25 , 4876-4882.

Wiedemann, C.R.W. (1830) Aussereuropäische Zweiflügelige Insekten. Zweiter Theil, Schulzische Buchhandlung, Hamm, 684 pp.

Wilkinson, G.S. \& Dodson G.N. (1997) Function and evolution of antlers and eye stalks in flies. In: Choe J. \& Crespi B. (Eds) The Evolution of Mating Systems in Insects and Arachnids, Cambridge University Press, Cambridge, 310328. 
